Article

\title{
Exploring Latent Topics and Research Trends in Mathematics Teachers' Knowledge Using Topic Modeling: A Systematic Review
}

\author{
Sunghwan Hwang ${ }^{1}$ and Eunhye Cho ${ }^{2, *}$ \\ 1 Department of Mathematics Education, Seoul National University of Education, Seoul 06637, Korea; \\ ihwang413@gmail.com \\ 2 Department of Education Studies, Stonehill College, North Easton, MA 02357, USA \\ * Correspondence: echo@stonehill.edu; Tel.: +1-508-565-1945
}

Citation: Hwang, S.; Cho, E. Exploring Latent Topics and Research Trends in Mathematics Teachers' Knowledge Using Topic Modeling: A Systematic Review. Mathematics 2021, 9, 2956. https://doi.org/ $10.3390 /$ math 9222956

Academic Editor: Luis Carlos Contreras-González

Received: 29 October 2021 Accepted: 18 November 2021 Published: 19 November 2021

Publisher's Note: MDPI stays neutral with regard to jurisdictional claims in published maps and institutional affiliations.

Copyright: (c) 2021 by the authors. Licensee MDPI, Basel, Switzerland. This article is an open access article distributed under the terms and conditions of the Creative Commons Attribution (CC BY) license (https:// creativecommons.org/licenses/by/ $4.0 /)$.

\begin{abstract}
Mathematics teachers' knowledge is considered one of the most critical factors in instruction and student achievement. As such, various studies have focused on mathematics teachers' knowledge. Despite the expansion of the field, however, a systematic review was rarely implemented. Therefore, this study aimed to identify major research topics and trends on mathematics teachers' knowledge by analyzing abstracts of 3485 scholarly articles published from 1987 to 2021 . Using a text-mining technique, 11 underlying topics were found in the articles. The topics were classified based on their relationships and the following four groups were identified: "assessment", "teachers' knowledge for teaching", "students' knowledge and understanding", and "teachers' professional learning". Over time, the analysis of research trends showed that professional development is the most popular topic, followed by pedagogical content knowledge and students' mathematical understanding. Moreover, the popularity of these topics has not changed considerably over time. This study provides implications based on these results.
\end{abstract}

Keywords: mathematics teachers' knowledge; systematic review; research trends; topic modeling; Latent Dirichlet Allocation

\section{Introduction}

Mathematics teachers' knowledge has been identified as an important predictor of their instructional practices [1] and student learning outcomes [2]. Therefore, extensive studies have been implemented to enhance mathematics teachers' knowledge and identified the nature and components of it [3-8]. Aligned with increasing research on mathematics teachers' knowledge, limited literature reviews were conducted to synthesize previous studies. The studies included conceptualization of pedagogical content knowledge (PCK) [9], elementary teachers' knowledge for teaching mathematics [10], and assessment of mathematics teachers' knowledge [11]. While these studies synthesized previous studies and informed the direction for future studies on a certain topic, they could not provide overall research trends in mathematics teachers' knowledge.

Moreover, most studies examined less than 50 articles and adopted manual coding methods, resulting in inaccurate results due to tedious processes [12]. To overcome these limitations, researchers have suggested implementing topic modeling, which can analyze and categorize large text data based on computer algorithms [13]. Research on trends in mathematics teachers' knowledge with topic modeling helps researchers understand which topics have been studied from the past to the present and which topics have received increasing or decreasing attention over time [14]. Therefore, this study aimed to implement a systematic review of mathematics teachers' knowledge using all relevant articles with topic modeling. 
Components of mathematics teachers' knowledge are first discussed to gain insights into major research topics. The characteristics of the topic modeling method are then described to explain the statistical approach used in the study. Afterwards, research methods, results, and discussions are articulated.

\section{Literature Review}

\subsection{Components of Mathematics Teachers' Knowledge}

Due to the increasing awareness of the influences of mathematics teachers' knowledge on teaching quality and student achievements [15], research on mathematics teachers' knowledge has been growing. A study by Inglis and Foster [16] examined research trends of papers published in Educational Studies in Mathematics (ESM) and Journal for Research in Mathematics Education (JRME) for the past five decades, and they found that research on teacher knowledge was one of the most notable research topics since the 1980s, along with research on teacher beliefs. This research trend was partially influenced by Shulman's [17] influential work. Before this study, educators did not focus on teachers' PCK much. Instead, educators primarily focused on mathematics teachers' disciplinary knowledge $[7,18]$. However, several scholars found that teachers' content knowledge could not fully explain students' learning outcomes, which resulted in the realization of the importance of teachers' PCK suggested by Shulman [7,16,18].

Shulman [17] categorized teacher knowledge into subject matter content knowledge (SCK), PCK, and curricular knowledge. Shulman [17] explained that SCK refers to knowledge of facts, concepts, and structures of a subject domain, whereas PCK is a "special amalgam of content and pedagogy" (p. 8), including knowledge of instructional strategies and representation and knowledge of students' (mis)conceptions. A year later, Shulman [19] proposed other components of teachers' knowledge, such as knowledge of learners and their characteristics and knowledge of educational contexts. However, he especially emphasized the importance of PCK, as it is specialized knowledge used for teaching and distinguished teachers' knowledge from other disciplinary specialists.

Meanwhile, Shulman's conceptualization of teacher's knowledge has been criticized due to a lack of empirical evidence. Furthermore, Shulman regarded teachers' knowledge as a relatively static view and did not consider dynamic and situational aspects of teaching in classrooms [9]. Therefore, mathematics educators have conducted empirical studies to identify components of mathematics teachers' knowledge, not teachers of other subjects. For example, Marks [20] examined elementary mathematics teachers and proposed the following four components of PCK: subject matter for instructional purposes, students' understanding of the subject matter, media for instruction in the subject matter, and instructional processes for the subject matter. Moreover, Depaepe et al. [9] conducted a systematic review of mathematics teachers' PCK and reported that most scholars viewed students' (mis)conceptions and difficulties and instructional strategies and representations as components of PCK. Moreover, some scholars included curriculum and media [21], math tasks and cognitive demands [22], and context knowledge [23] as components of PCK.

Other scholars proposed different frameworks of mathematics teacher's knowledge by considering both SCK and PCK (e.g., [3,5-8]). The components of the individual framework are shown in Table 1. Davis and Simmt [3] presented Teachers' Mathematics for Teaching framework, which consisted of mathematical objects, curriculum structures, classroom collectivity, and subjective understanding. Furthermore, Rowland et al. [6] and Ball et al. [7] proposed Knowledge Quartet and Mathematical Knowledge for Teaching frameworks, respectively. More recently, Carrillo-Yañez et al. [8] suggested the Mathematics Teacher's Specialized Knowledge (MTSK) model building upon the frameworks of Shulman [17] and Ball et al. [7]. MTSK consists of mathematical knowledge (MK) and PCK. MK included knowledge of the topic (content), knowledge of the structure of mathematics (connection between mathematical items), and knowledge of practices in mathematics (knowledge used for solving mathematical tasks). PCK concerned knowledge of features of learning mathematics, knowledge of mathematics teaching, and knowledge of mathematics learning 
standards. Unlike previous studies, MTSK contained teachers' beliefs about mathematics and mathematics teaching and learning to emphasize the reciprocal relationship between teachers' mathematical knowledge and beliefs [8,24]. While these studies provided information on the nature and components of mathematics teachers' knowledge, there is still limited information on what kinds of studies (i.e., research topics) have been conducted on mathematics teachers' knowledge and how they have evolved over time.

Table 1. Component of mathematics teachers' knowledge.

\begin{tabular}{cc}
\hline \multicolumn{1}{c}{ Authors } & \multicolumn{1}{c}{ Components } \\
\hline Shulman [17] & $\mathrm{SCK}^{1}, \mathrm{PCK}^{2}$, curriculum knowledge $^{-}$ \\
\hline Shulman [19] & $\begin{array}{l}\mathrm{SCK}, \text { general PCK, curriculum knowledge, PCK, knowledge } \\
\text { of learners and their characteristics, knowledge of } \\
\text { educational contexts, knowledge of educational ends, } \\
\text { purposes, values, their philosophical and historical grounds }\end{array}$ \\
\hline
\end{tabular}

\begin{tabular}{ll}
\hline Rowland et al. [6] $\quad$ mathematical objects, curriculum structures, classroom \\
collectivity, and subjective understanding
\end{tabular}

Davis and Simmt [3] _ foundation, transformation, connection, and contingency

\begin{tabular}{ll}
\hline Peng [5] & $\begin{array}{l}\text { mathematics content, teaching method and learning } \\
\text { method, teaching procedure }\end{array}$ \\
\hline Ball et al. [7] & $\begin{array}{l}\text { Subject matter knowledge (common content knowledge, } \\
\text { specialized content knowledge, and horizon content } \\
\text { knowledge) } \\
\text { PCK (knowledge of content and students, knowledge of } \\
\text { content and teaching, and knowledge of content and } \\
\text { curriculum) }\end{array}$ \\
\hline Carrillo-Yañez et al. [8] & $\begin{array}{l}\text { MK }{ }^{3} \text { (knowledge of topic, knowledge of the structure of } \\
\text { mathematic, and knowledge of practices in mathematics) } \\
\text { PCK (knowledge of features of learning mathematics, } \\
\text { knowledge of mathematics teaching, and knowledge of } \\
\text { mathematics learning standards) } \\
\text { Beliefs about mathematics and about mathematics teaching } \\
\text { and learning }\end{array}$ \\
\hline
\end{tabular}

$\overline{{ }^{1} \text { SCK: subject matter content knowledge, }{ }^{2} \text { PCK: pedagogical content knowledge, }{ }^{3} \text { MK: mathematical knowledge. }}$

\subsection{Topic Modeling}

Topic modeling is one of the analytical methods in the field of text mining. Topic modeling is a computational method that discovers abstract topics that underlie a corpus. Through statistical modeling, typically, a large collection of documents (i.e., corpus) is classified into a small number of topics [25]. Topics are statistically derived based on the words that frequently co-occur within a corpus. Considering that it is a fully automated and inductive process, there is no firmly pre-established idea of what topics would come out of the documents and how topics are related to words and documents [13].

Latent Dirichlet Allocation (LDA) has been widely implemented as a tool for topic modeling, developed by computer linguists Blei et al. [25]. The term "latent" refers to that the model discovers the topics that are not directly observed, but could infer them from the words in the documents [14]. Dirichlet indicates the algorithm of LDA that follows 
a Dirichlet process, a multivariate generalization of the Beta distribution. LDA assumes that documents consist of words that share a certain topic, and a list of hidden topics can be discovered by the frequency of observed words [12]. Moreover, the distribution of topics in a document and the distribution of words in a topic are assumed to be Dirichlet distribution. The scheme of the LDA algorithm is represented as a probabilistic graphical model in Figure 1. The algorithm is formally described with notations as follows [13].

$\beta_{k}$ : Topics are $\beta_{1: k}$, where each $\beta_{k}$ is a distribution over words at left. It follows Dirichlet distribution.

$\theta_{d}$ : The topic proportions for the $d$ th document are $\theta_{d}$, where $\theta_{d, k}$ is the topic proportion for topic $\mathrm{k}$ in document $\mathrm{d}$ (the histogram labeled document-topic probability. Distribution). $\theta \sim \operatorname{Dir}(\alpha)$.

$Z_{d, n}$ : The topic assignment for the $d$ th document, where $Z_{d, n}$ is the topic assignment for the $n$th word in document $d$ (coins grouped in a colored topic group under Topics [k]). Zn $\sim$ Multinomial $(\theta)$.

$W_{d, n}$ : The observed nth word in document $d . \mathrm{P}\left(W_{d, n} \mid Z_{d, n}, \beta\right)$.

$\mathrm{N}$ : $\quad$ The collection of words within the document.

D: The collection of documents within the corpus.

K: $\quad$ The collection of topics.

$\alpha$ : $\quad$ The hyperparameter representing a document-topic density.

$\eta$ : $\quad$ The hyperparameter representing a topic-word density.

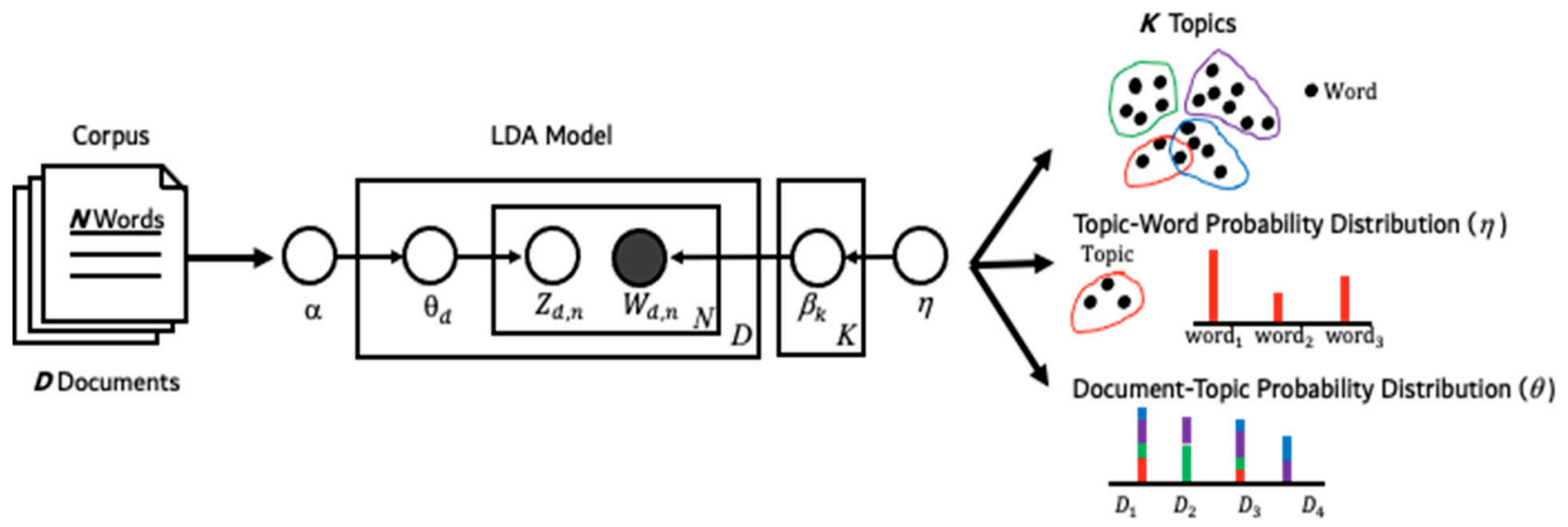

Figure 1. Graphical model for the LDA process adapted from Blei [13].

In Figure 1, a rectangle is a plate indicating replication. A node in the LDA model is a random variable labeled according to its role in the generative process. The observed node, the words of the documents $\left(W_{d, n}\right)$, are shaded, as shown in the figure. The hidden notes-topic proportions $\left(\theta_{d}\right)$, assignments $\left(Z_{d, n}\right)$, and topics $\left(\beta_{k}\right)$-are unshaded. These hidden variables are inferred by an observed variable $W_{d}$ and two hyperparameters $\alpha$ and $\eta$.

We describe the key products derived from the LDA model on the right side of the figure. These three visual models (K topics; topic-word probability distribution; documenttopic probability distribution) represent what process was performed when having a collection of documents with $\mathrm{N}$ words. D and w indicate corpus and each document, respectively. Based on the observed $n$th word in document $d\left(W_{d, n}\right)$, the document-topic probability distribution $\left(\theta_{d}\right)$ and topic-word probability distribution $\left(\beta_{k}\right)$ are inferred. LDA algorithm generates a set of the number of topics $(K)$. Then, research determines an "optimal" K number based on the perplexity value [16]. The detailed information on how to determine $\mathrm{K}$ is presented in the Method section of the study.

A wide number of educators currently use the text mining approach (e.g., topic modeling) to conduct a systematic review. The topics included language of mathematics teaching [26], artificial intelligence in mathematics education [27], and research trends in mathematics education [16]. All these studies identified latent topics in large unstructured 
numbers of text data and provided research trends. To the best of our knowledge, however, there are no systematic reviews examining research on mathematics teachers' knowledge with a text mining approach. This gap necessitates additional studies on mathematics teachers' knowledge to enhance our understanding of the field.

\subsection{Current Study}

Previous studies on mathematics teachers' knowledge provided information on the nature and components of it. However, there is still limited information regarding major research topics on mathematics teachers' knowledge and how they have evolved over time. While limited literature reviews of mathematics teachers' knowledge have been conducted, most of them examined a certain field with less than 50 articles (e.g., [10]). Therefore, this study conducted a systematic review on mathematics teachers' knowledge with all relevant articles after Shulman's [17] study. The LDA was particularly implemented to examine the large corpus of data. The LDA allows researchers to identify the latent research topics [12], which might not be discussed by previous literature reviews but widely studied topics by researchers. Moreover, the LDA helps researchers understand how research topics were associated [28] and how research interests on research topics have changed over time [16]. The research questions of the current study are as follows:

RQ 1: How did overall research trends on mathematics teachers' knowledge evolve?

RQ 2: What were the frequently used words in the abstract?

RQ 3: What were the major research topics?

RQ 4: How and to what extent were the major research topics associated?

RQ 5: How did individual research topic trends evolve?

\section{Materials and Methods}

\subsection{Data Collection and Screening}

To find the articles, the following three research engines were used: Web of Science, Eric, and PsycInfo. These engines were widely used in educational research for the systematic review $[9,29]$. We searched articles containing all three terms (i.e., search terms) in abstract: "mathematics", "teacher or teachers", and "knowledge". As an abstract describes research purposes, contexts, and problems, and major findings, examining abstracts could reveal major research topics of collected data [12]. A total of 12,544 articles (4384 in Web of Science, 5544 in Eric, and 2616 in PsycInfo) were retrieved. Then, the following inclusion and exclusion criteria were applied to select relevant articles (see Table 2). Figure 2 shows the data collection, identification, and filtering process of the study. First, we selected articles published in peer-reviewed journals and excluded dissertations or theses to guarantee scholarly quality. Second, we included articles written in English (2571 in Web of Science, 3127 in Eric, and 1019 in PsycInfo). All articles then were imported into EndNote 20 , and duplicated articles were deleted $(\mathrm{k}=4574)$. Third, we read the title and abstract of individual articles and excluded studies examining non-mathematics teachers' knowledge (e.g., science teachers' knowledge). We read the full text to guarantee authenticity when we could not ensure whether an article was aligned with the research purpose of this study. Fifth, we excluded articles published before 1987 as Shulman's [17] study was introduced in 1986. Using these selection criteria, a total of 3485 articles were retrieved.

Table 2. Inclusion and exclusion criteria for data collection.

\begin{tabular}{lll}
\hline \multicolumn{1}{c}{ Inclusion Criteria } & \multicolumn{1}{c}{ Exclusion Criteria } \\
\hline - $\quad \begin{array}{ll}\text { Examined in-service or preservice } \\
\text { mathematics teachers' knowledge }\end{array}$ & - & Examined non-mathematics subject \\
- Written in English & - & $\begin{array}{l}\text { Dapertations or theses } \\
\text { Pathout abstracts and full texts }\end{array}$ \\
- Peer-reviewed articles & - & Published before 1987 \\
\hline
\end{tabular}




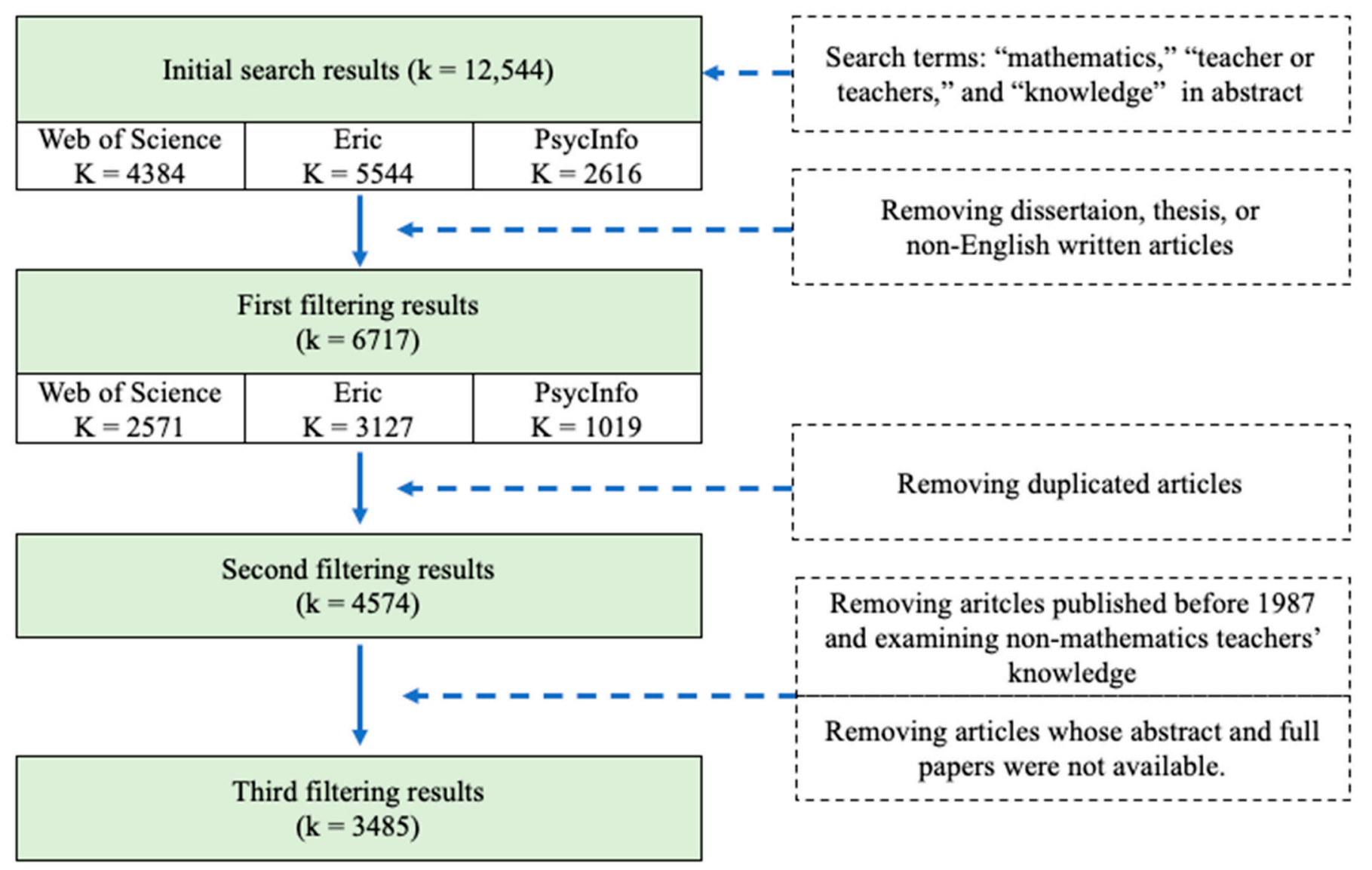

Figure 2. Data selection process.

\subsection{Data Analysis}

\subsubsection{Pre-Processing}

Applying topic modeling techniques to corpora requires converting documents to "cleaner" data using various pre-processing treatments [30]. This study adopted a programming language $R$, and conducted two distinct pre-processing steps as common in topic modeling: stopwords removal and stemming [12]. First, we filtered out stopwords like prepositions, pronouns, conjunctions, numbers, and punctuation marks. We also removed words that are commonly used in research articles but would not be topic-specific such as "mathematics", "knowledge", "purpose", "results", and "implication". Then, we conducted stemming process by using a SnowballC package in $R$. This step gives a single stemmed form of a word from different versions of words by removing plurals and inflections. The word "teachers", for example, is converted to the word "teacher" through a stemming process. The stemming process enhances interpretability without having an important effect on the outcome of LDA [30]. The pre-processing pipeline left 262,582 words in the study data.

\subsubsection{Perplexity}

Perplexity indicates the optimal number of topics of collected data [25]. Thus, perplexity determines the quality of the model, how well an LDA model predicts collected data. A CaoJuan2009 [31] package was used to find an optimal number of topics for the LDA model. The smaller value of perplexity represents the better model fit. Figure 3 illustrates that a line appears to level off when the number of topics is 11 , and the values of perplexity in the range of 11-15 and 18-20 are quite similar to each other. Therefore, we determined the optimal number of topics is 11 as it has the lowest perplexity value, which in turn, gives the best generalization performance [32]. 


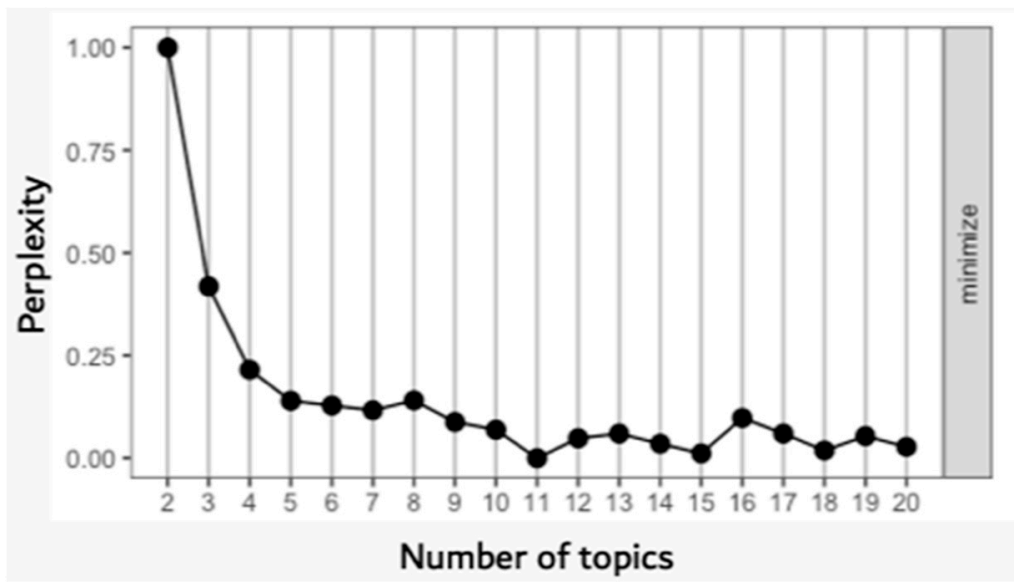

Figure 3. Perplexity of topic model.

\subsubsection{Naming Research Topic}

In this study, documents data are the abstracts of scholarly articles, and topics are inferred on the basis of words included in the abstracts. The LDA algorithm is an entirely data-driven technique with no priori coding scheme used [25]. However, the name of each research topic should be determined by researchers. A three-step approach was adopted to identify topic labels. First, we checked on each topic's top 15 characteristic words, which revealed the highest proportions within a topic $\left(\beta_{k}\right)$. Second, we created a word cloud of each topic with the top 50 words using a wordcloud 2 package. Third, we inspected the top 20 articles with the highest proportion of words $\left(\theta_{d}\right)$ from each topic. For example, the top 15 words in a topic identified by LDA algorithm were "children", "learn", "develop", "teacher", "skill”, "curriculum", "literacy", "preschool”, "instruct", "student", "childhood", "read", "parent", "numeracy", and "kindergarten". In addition, a word cloud with top 50 words was created as exemplified in Figure 4. Moreover, the topic included articles, such as "Mathematical pedagogical content knowledge of early childhood teachers: A standardized situation-related measurement approach" [33]. Therefore, the topic was named Early Childhood Mathematics Education.

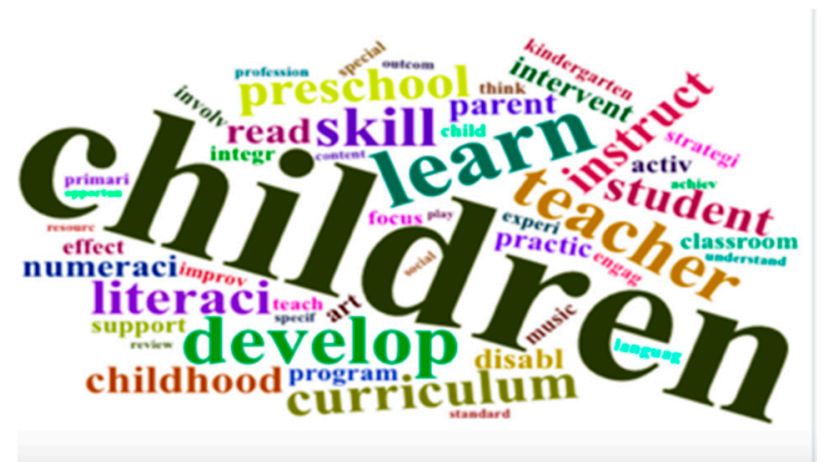

Figure 4. Word cloud of early childhood mathematics education.

\section{Results}

\subsection{Analysis of Overall Research Trends and Word Frequency}

To understand overall research trends of mathematics teachers' knowledge after 1986 (1987 current), the number of articles was analyzed based on their publication years (see Figure 5). In addition, Table 3 shows the number of publications for nearly a decade. Figure 5 and Table 3 show a gradual increment of publication over time. These findings imply that researchers have shown a growing interest in studying mathematics teachers knowledge since 1987. Studies published between 1987 and 1999 constitute only $4.3 \%$ of the studies $(n=153)$, whereas studies published between 2010 and 2021 constitute $77.9 \%$ 
$(n=2714)$ of all studies. Furthermore, as illustrated in Figure 5, more than 300 articles have been published every year since 2017. Although there is a slight decrease after 2020, it does not indicate a decrease in publications. As we collected data in August 2021, articles published after this date were not analyzed in the study.

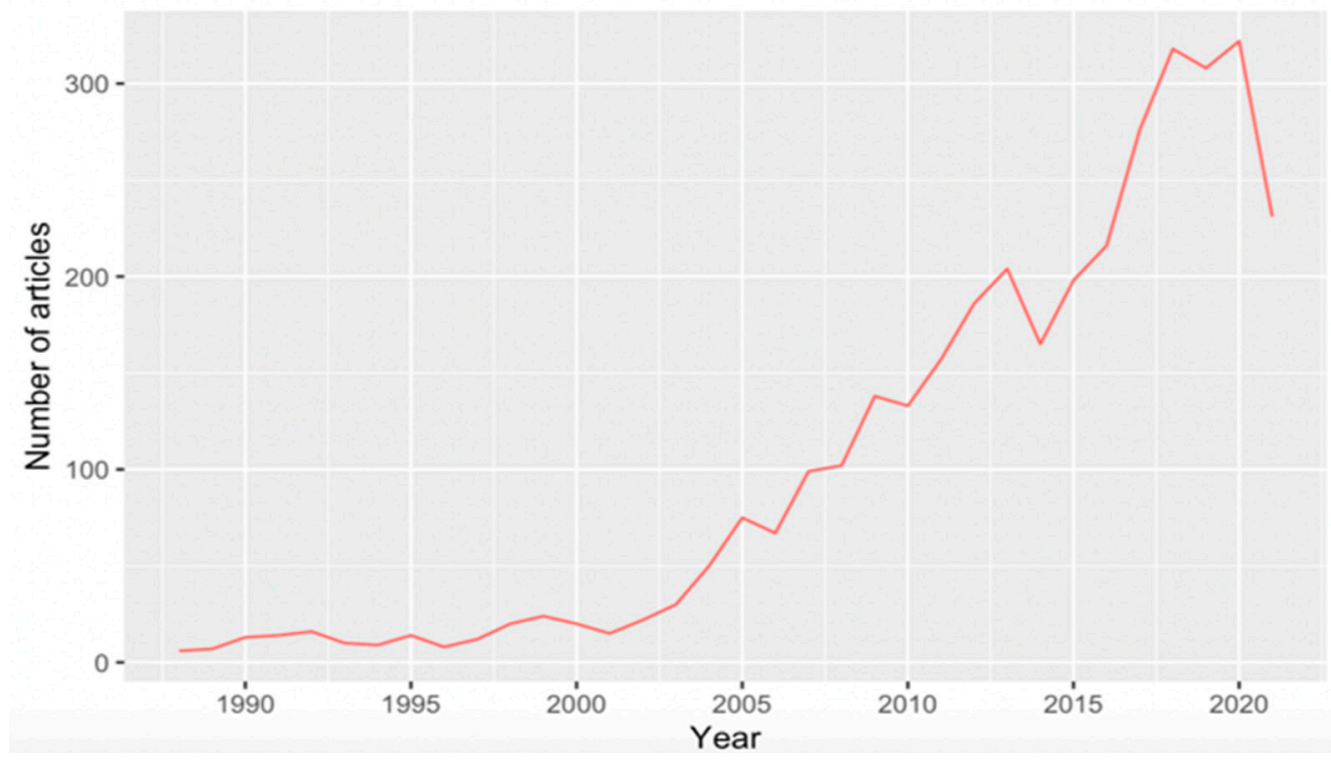

Figure 5. The number of the articles by publication years.

Table 3. Research trends by period.

\begin{tabular}{cc}
\hline Year Range & Number (\%) \\
\hline $1987-1999$ & $153(4.3 \%)$ \\
$2000-2009$ & $618(17.7 \%)$ \\
$2010-2021$ & $2714(77.9 \%)$ \\
Total & $3485(100 \%)$ \\
\hline
\end{tabular}

Figure 6 depicts the words with more than 1000 frequency in abstracts. The 15 most frequently used words were "teacher", "students", "teach", "learn", "develop", "preservice", "content", "practice' "understand", "classroom", "instruct", "professional", "pedagogy", "participation", and "concept". The combination of these words could represent key issues in the research on mathematics teachers' knowledge. For example, "professional" and "development" might represent a study on professional development to enhance mathematics teachers' knowledge. Therefore, the topic modeling was conducted to examine how the words were combined and categorized according to the topic. 


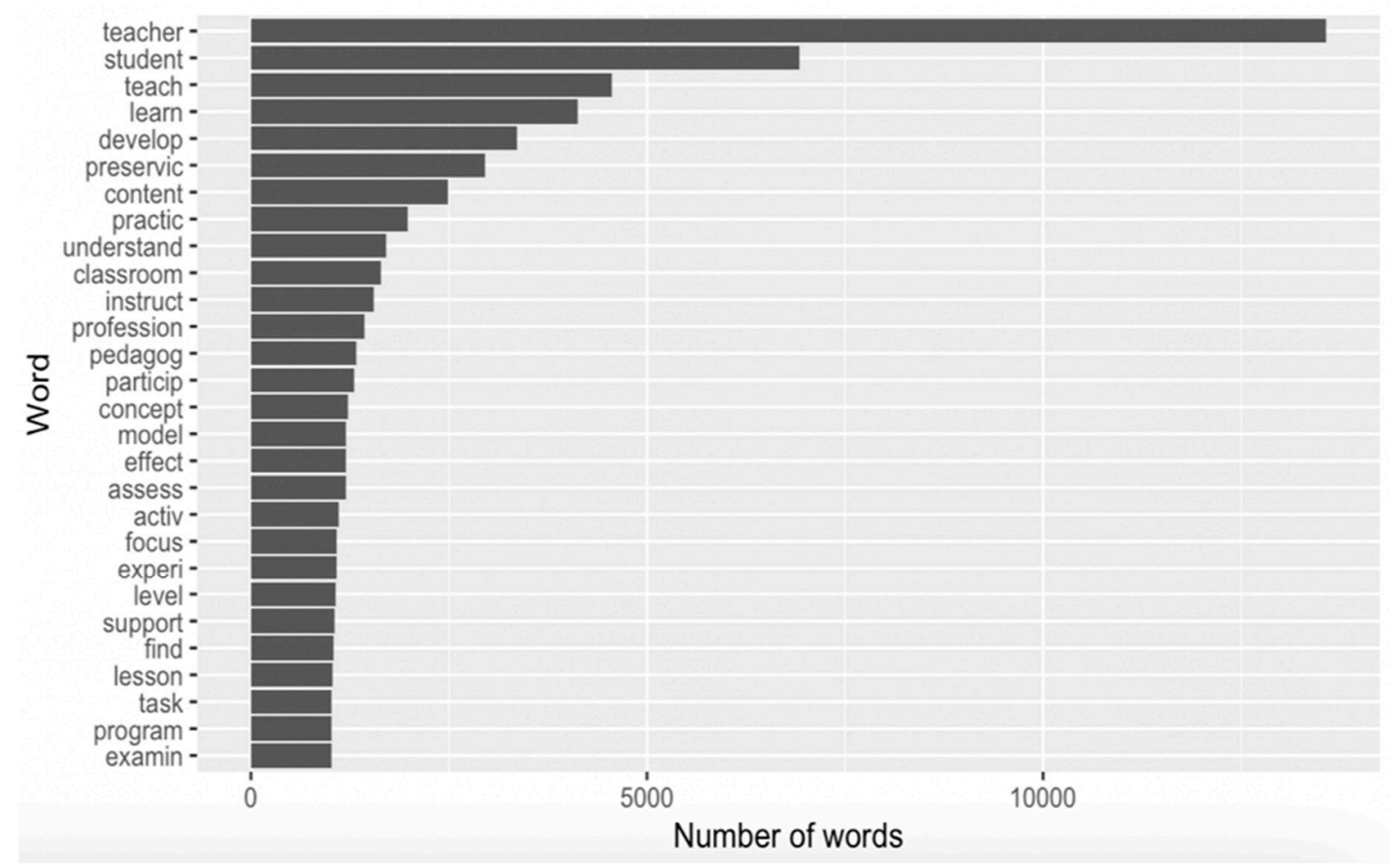

Figure 6. Words with more than 1000 frequency in abstracts.

\subsection{Major Research Topics}

Table 4 shows the labels of 11 topics derived from the LDA algorithm. The labels were named based on the top 15 characteristic words, word clouds (see Table 5), and representative articles of each topic. The components of mathematics teachers' knowledge discussed by previous scholars were also considered (see Table 1). It is important to note that while on the surface some topic labels seemed not related to mathematics teachers knowledge, all topics were strongly related to it as we only selected articles containing "mathematics", "teacher", "knowledge" in abstracts.

Topic1 (T1) was named "Professional Development", as the characteristic words included learn, professional, development, teacher, and lesson. Moreover, article in T1 were associated with lesson study and professional development. Topic 2 (T2) was named "Student Mathematical Understanding" because the characteristic words assigned to this topic delved into the students' error, think, solution, strategy, reasoning, and problem solving. Moreover, articles in T2 discussed students' difficulties and understanding in problem solving.

Topic 3 (T3) contained words associated with the measurement of students' and teachers' knowledge, such as assess, measure, level, test, and standard; thus, it was named "Knowledge Assessment". Topic 4 (T4) was named "Content Knowledge of Students" as it included student, geometry, algebra, multiplication, concept, and conceptual (understanding) as characteristic words. Moreover, the articles in T4 examined mathematical content that students learn in mathematics classrooms. As characteristic words, Topic 5 (T5) included learn, teacher, teach, integration, technology, computer, ICT, and classroom. Moreover, T5 contained articles examining mathematics teachers' learning and use of educational technology. Thus, T5 was named "Learning and Use of Educational Technology". Topic 6 (T6) was named "Preservice Teachers" as it involved preservice and teacher as characteristic words and contained articles examining preservice teachers' mathematical knowledge.

Topic 7 (T7) was named "Pedagogical Content Knowledge" as the characteristic words included pedagogy, content, and PCK, and articles in T7 discussed PCK of mathematics teachers. Topic 8 (T8) was named "Early Childhood Mathematics Education" as it has the words, such as children, preschool, and childhood. Moreover, articles in T8 examined 
mathematics teaching and learning for preschoolers. Topic 9 (T9) was named "Content Knowledge of Teachers", as the characteristic words included teacher, geometry, concept, theory, proof, and define. Moreover, studies examining teachers' mathematics content knowledge, such as zero exponent and right angles, were included in T9.

Topic 10 (T10) included characteristic words about instructional methods (e.g., activity, skill, and model) and student achievement (e.g., effect, achievement, and improvement). Moreover, articles in T10 examined the effects of teachers' implementation of a certain instructional method (e.g., group work) on student achievement. Thus, T10 was named "Instructional Methods and Student Achievement". Topic 11 (T11) included the characteristic words associated with sociocultural contexts, such as culture, social, identity, country, and context. Moreover, the articles discussed teaching students with diverse sociocultural backgrounds. For example, T11 contained articles that addressed minority students in mathematics classrooms [34]. Thus, T11 was named "Knowledge of Sociocultural Context".

Table 4. Topic labels, characteristic words, and sample representative article of each topic.

$\begin{array}{r}\text { Topic Label } \\ \hline \text { T1. Professional Development }\end{array}$

T2. Student Mathematical Understanding

T3. Knowledge Assessment

T4. Content Knowledge of Students

T5. Learning and Use of Educational Technology

T6. Preservice Teachers

T7. Pedagogical Content Knowledge

T8. Early Childhood Mathematics Education

T9. Content Knowledge of Teachers

T10. Instructional methods and student achievement

T11. Knowledge of Sociocultural Context

Top 15 Characteristic Words

teacher, teach, develop, learn, practice, professional, lesson, classroom, student support, instruction, focus, content, experience, participation

student, teacher, task, solve, strategy, reasoning, think, understand, learn, error, process, solution, classroom, cognitive, explain

assess, student, teacher, test, measure, perform, level, achievement, grade, score, skill, competence, item, standard, develop

student, understand, teacher, concept, algebra, represent, learn, instruct, function, reason, multiplication, connect, develop, conceptual, standard

technology, teach, teacher, integration, learn, develop, computer, history, ICT, tool, digital, approach, practice, process, inform

preservice, teacher, elementary, fraction, teach, participation, pupil, understand, concept, content, conceptual, course, find, primary, examine

teacher, content, teach, pedagogy, preservice, pck, subject, belief, secondary, develop, training, level, attitude, program, primary

children, learn, develop, teacher, skill, curriculum, literacy, preschool, instruct, student, childhood, read, parent, numeracy, kindergarten

teacher, geometry, concept, model, discourse, construct, theory, participation, process, student, proof, dynamic, develop, understand, define

student, learn, model, effect, teacher, activity, achievement, class, motivation, classroom, test, control, skill, improvement, experiment

teacher, student, culture, curriculum, language, social, teach, learn, practice, identity, develop, context, country, learn, reform
Sample Representative Article

Using the knowledge quartet to develop mathematics content knowledge: The role of reflection on professional development [35]

Grade 9 mathematics learners' strategies in solving number-pattern problems [36]

Analyzing connections between teacher and student topic-specific knowledge of lower secondary mathematics [37]

An analysis of elementary school children's fractional knowledge depicted with circle, rectangle, and number line representations [38]

Classroom-based professional expertise: A mathematics teacher's practice with technology [39]

Facilitating preservice teachers' development of mathematics knowledge for teaching arithmetic operations [40]

Teaching teachers to teach Boris: a framework for mathematics teacher educator pedagogical content knowledge [41]

Mathematical pedagogical content knowledge of early childhood teachers: A standardized situation-related measurement approach [33]

Teachers' knowledge of the nature of definitions: The case of the zero exponent [42]

Implementing effective group work for mathematical achievement in primary school classrooms in Hong Kong [43]

Investigating practices of highly successful mathematics teachers of traditionally underserved students [34] 
Table 5. Word clouds of each topic.

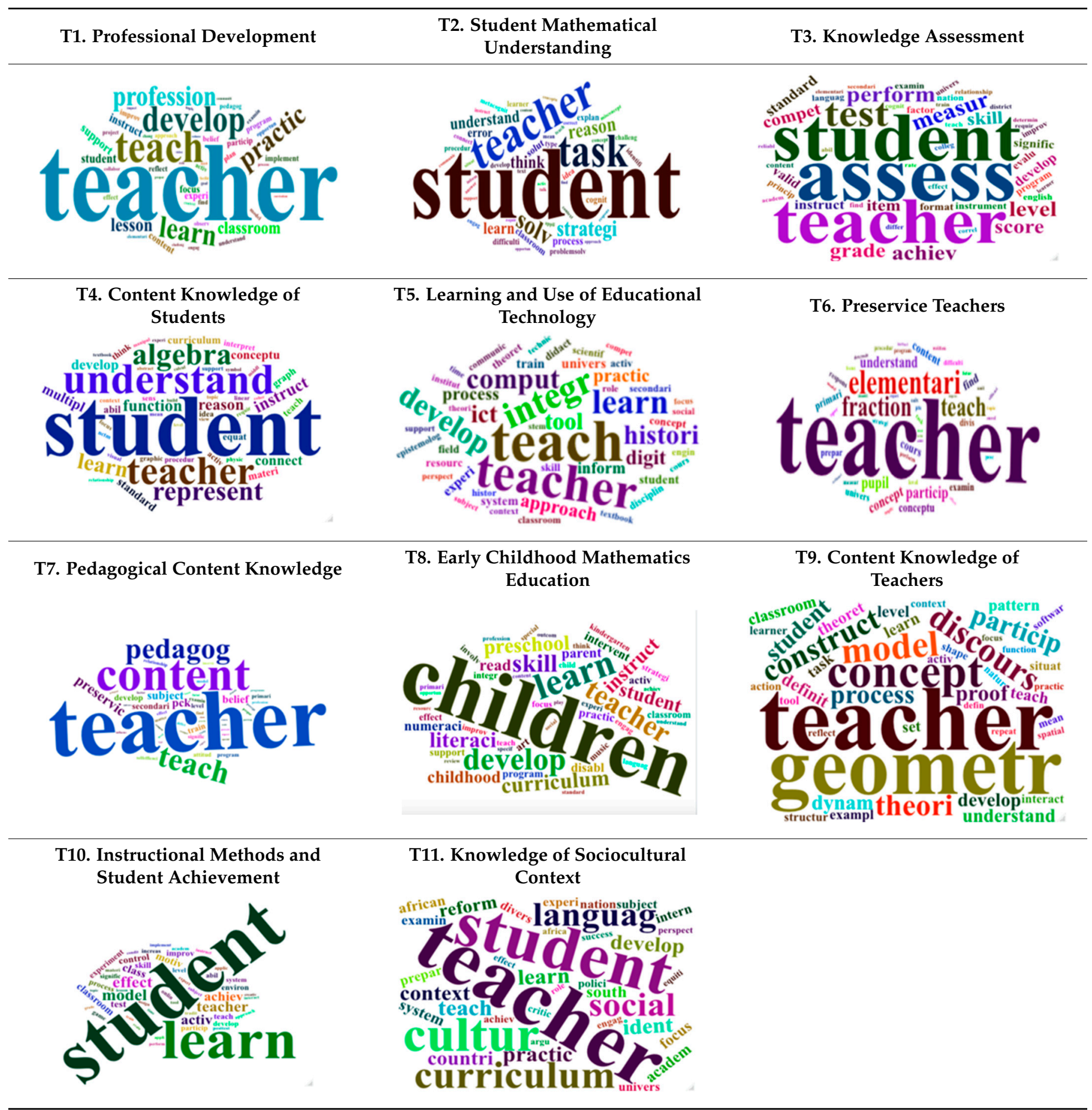

Note: Word cloud was created using the top 50 words of each topic. The larger word indicates the higher frequency in the topic.

The $\mathrm{R}$ package LDAvis was employed to create an intertopic distance map (see Figure 7), which helped researchers examine the relationship between topics [28]. The area size of the circle represents the proportion of the topic in the entire corpus. For example, T1 has the largest area size, which implies that there have been several studies on professional development (T1) to improve mathematics teachers' knowledge. Moreover, the distance between circles indicates the relationship between topics. The shorter distance indicates a closer relationship. Therefore, the topics in the same quadrant are likely to discuss a similar group of studies. For example, T7, T9, and T11 are located in the second quadrant and all of those topics discussed mathematics teachers' knowledge, including pedagogical content 
knowledge, content knowledge, and knowledge of the sociocultural context. However, it is possible that topics located in the different quadrants could be grouped together into the same group, when the distance between them is short [28]. For example, T1 and T6 could be grouped as the same group due to their short distance. Therefore, it is important to examine not only intertopic distance map, but also topic labels, characteristic words, and representative articles of each topic when reclassifying topics.

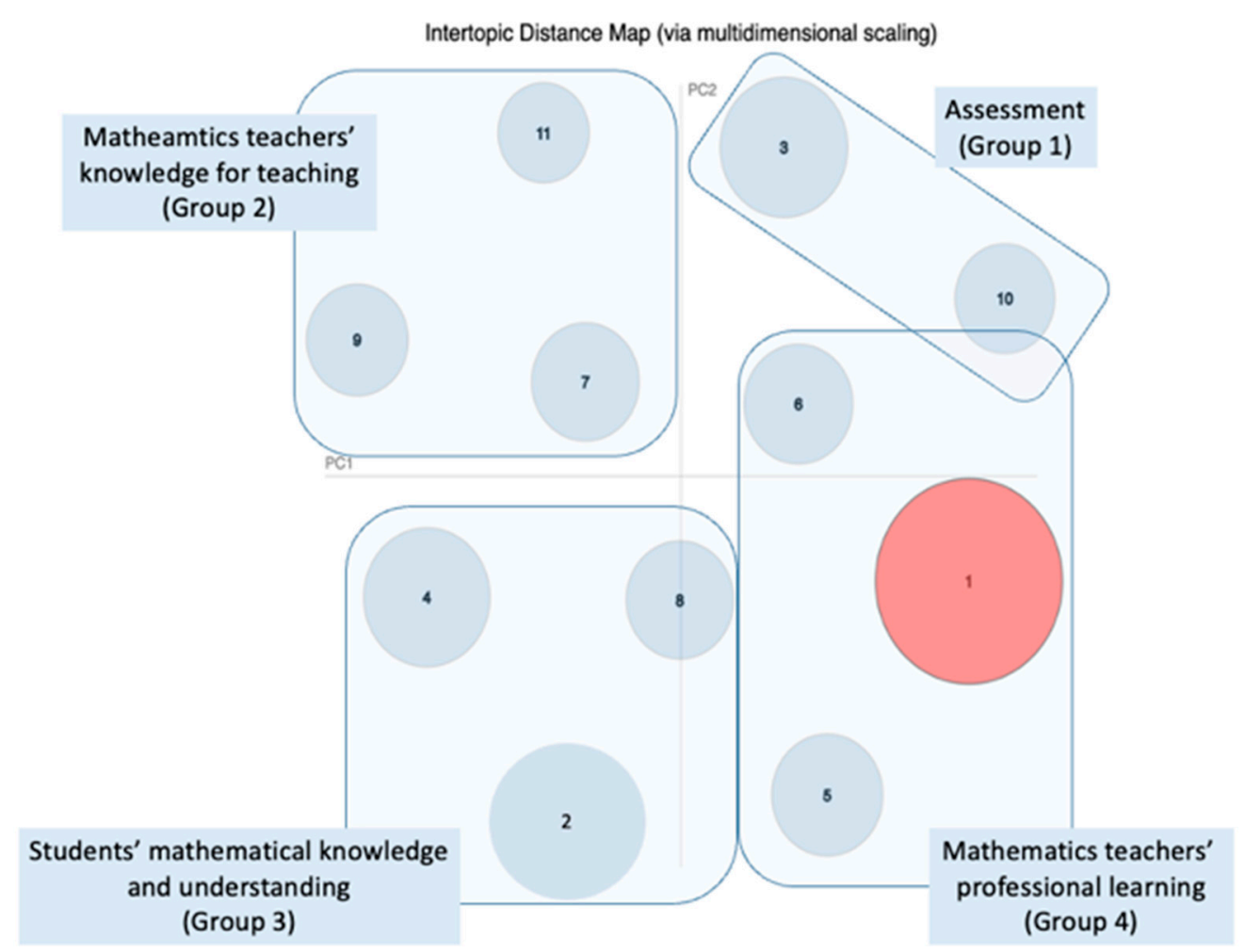

Figure 7. Intertopic distance map between topics.

We reclassified 11 topics into four research groups. The first group was concerned with assessment, including assessing teachers' and students' knowledge (T3) and student achievement (T10). The second group was a group about mathematics teachers' knowledge for teaching, including pedagogical content knowledge (T7), content knowledge (T9), and knowledge of the sociocultural context (T11). The third group was concerned with students' mathematical knowledge and understanding, including student mathematical understanding (T2), content knowledge of students (T4), and mathematics learning of preschoolers (T8). The fourth group delved into mathematics teachers' professional learning, such as professional development for in-service teachers (T1), learning of preservice teachers (T6), and learning of educational technology (T5).

\subsection{Topic Trend Analysis}

To examine the research trend over time, the years of publications were divided into three groups. As illustrated in Figure 8, we examined the proportional change of each topic over time by plotting a line graph. Specifically, we split the years of publications as follows: (a) 1987-1999 (red line), (b) 2000-2009 (green line), and (c) 2010-2021 (blue line). The analysis revealed that the three lines were quite similar regardless of time periods, which implies that the interest in a topic did not dramatically change over time. Across all topics, the highest difference between any two groups was only $3 \%$; T2 took $10.4 \%$ in 1987-1999 and 7.4\% in 2000-2009 (see Table 6). Even T6, T7, and T9 showed less than 1\% proportional change across three time periods. 


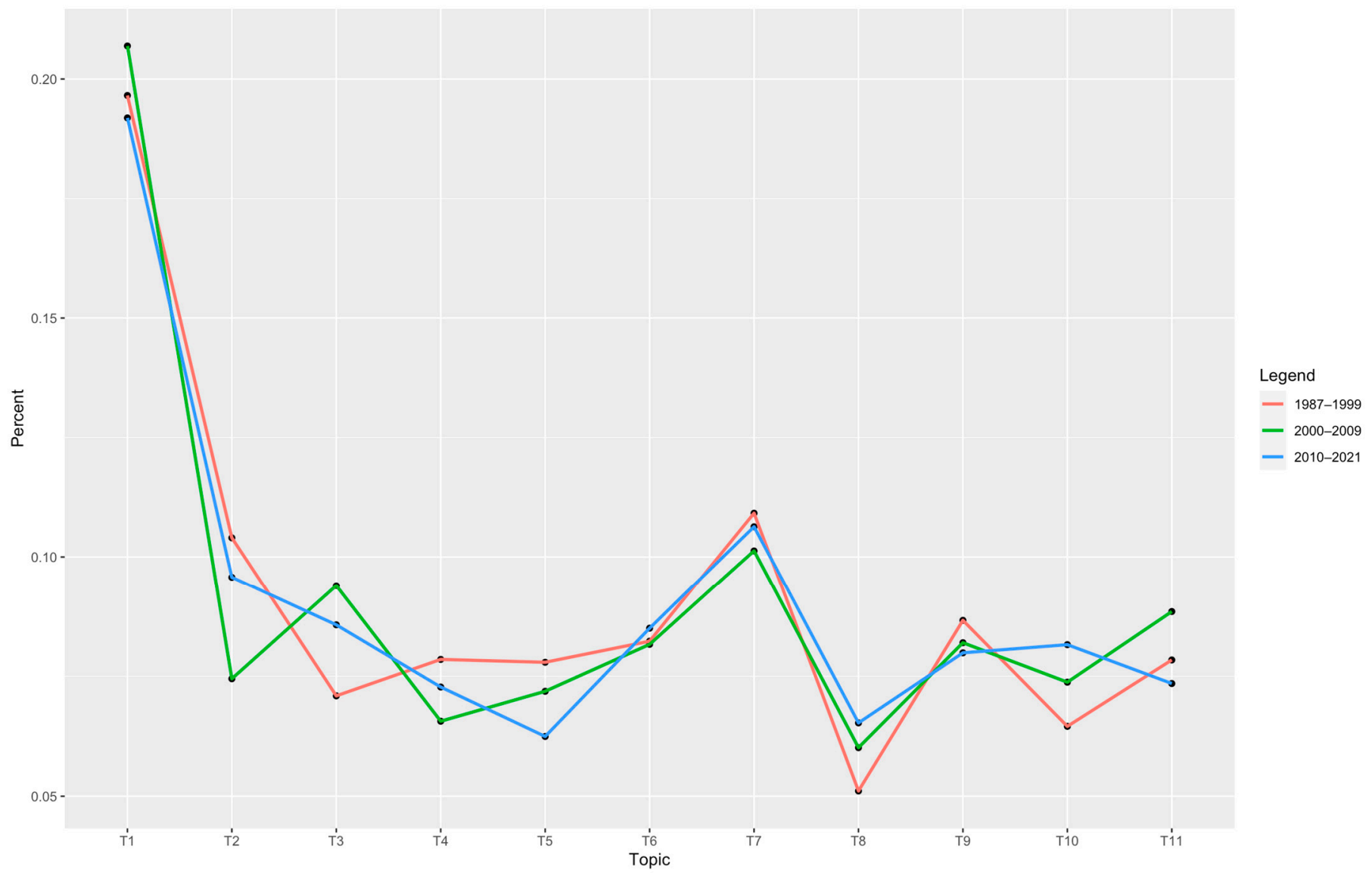

Figure 8. Change in topic proportion by period (\%).

Table 6. Topic proportion by period (\%).

\begin{tabular}{cccccccccccc}
\hline Period & T1 & T2 & T3 & T4 & T5 & T6 & T7 & T8 & T 9 & T10 & T11 \\
\hline 1987-1999 & 19.7 & 10.4 & 7.1 & 7.8 & 7.8 & 8.2 & 10.9 & 5.1 & 8.7 & 6.5 & 7.8 \\
\hline 2000-2009 & 20.7 & 7.4 & 9.4 & 6.6 & 7.2 & 8.2 & 10.1 & 6.0 & 8.2 & 7.4 & 8.8 \\
\hline 2010-2021 & 19.2 & 9.6 & 8.6 & 7.3 & 6.2 & 8.5 & 10.6 & 6.5 & 8.0 & 8.2 & 7.3 \\
\hline \multirow{2}{*}{ M (SD) } & 19.9 & 9.1 & 8.4 & 7.2 & 7.1 & 8.3 & 10.5 & 5.9 & 8.3 & 7.4 & 8.0 \\
& $(0.8)$ & $(1.6)$ & $(1.2)$ & $(0.6)$ & $(0.8)$ & $(0.2)$ & $(0.4)$ & $(0.7)$ & $(0.4)$ & $(0.9)$ & $(0.8)$ \\
\hline
\end{tabular}

Moreover, T1 (19.9\%) was the most studied topic followed by T7 $(10.5 \%)$ and T2 (9.1\%), whereas T8 (5.9\%) was the least studied topic followed by T5 (7.1\%) and T4 (7.2\%). However, some topics (T8 and T10) showed a slight increase while some (T5) showed a decrease over time. For example, the proportion of T8 was increased from $5.1 \%$ to $6.0 \%$ to $6.5 \%$, whereas the proportion of $\mathrm{T} 5$ was decreased from $7.8 \%$ to $7.2 \%$ to $6.2 \%$.

To capture research trends more closely, we created a line graph of each topic, which shows the proportional change by year (see Table 7). Each dot represents the proportion of a topic in a certain year. We also made a cubic line and 95\% confidence region based on the dots. Similar to previous discussions, the attention to topics did not substantially change over time, while there were few outliers (see T4 and T9 in Table 7). In sum, it is observed that research trends of mathematics teachers' knowledge have been sustained at the similar levels over time. 
Table 7. Change in topic proportion by year.

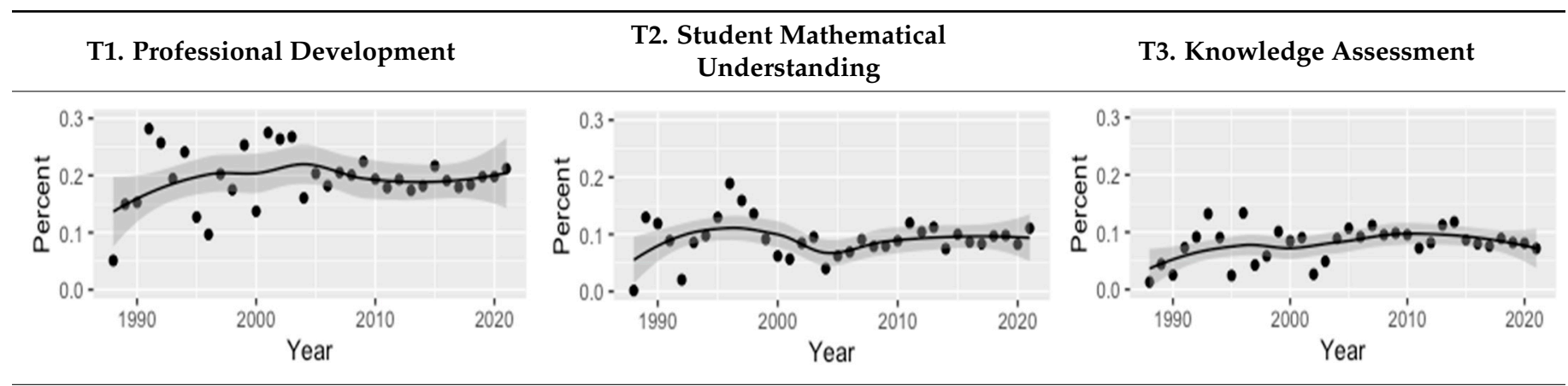

T4. Content Knowledge of Students

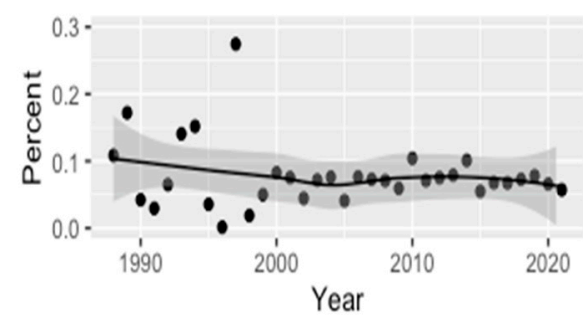

T7. Pedagogical Content Knowledge

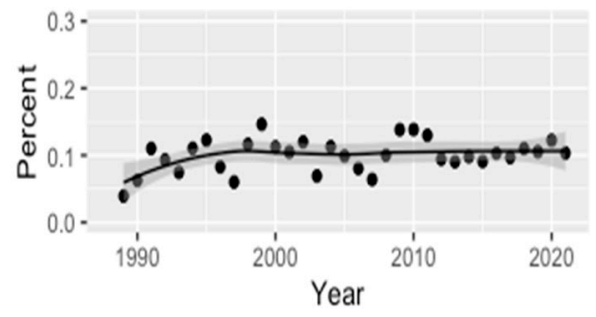

T10. Instructional Methods and Student Achievement

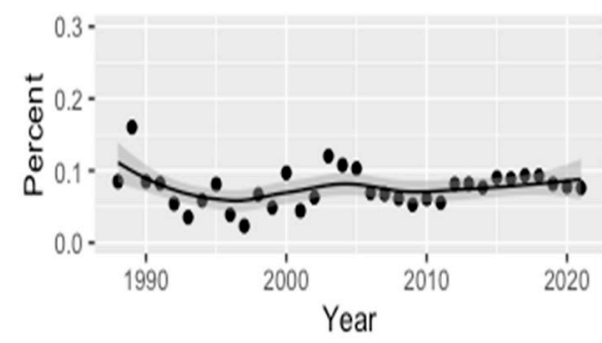

T5. Learning and Use of Educational Technology

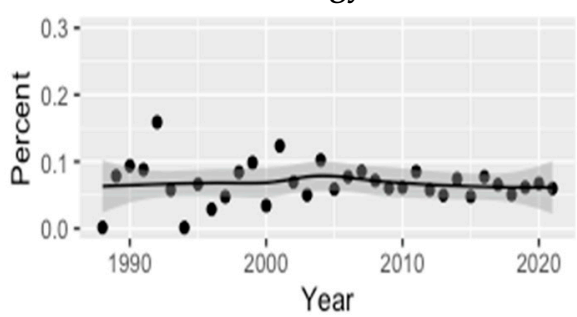

T8. Early Childhood Mathematics Education

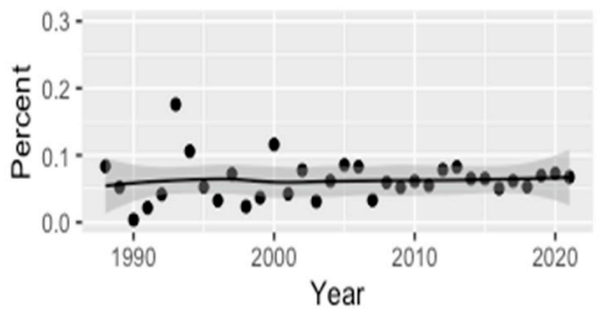

T11. Knowledge of Sociocultural Context

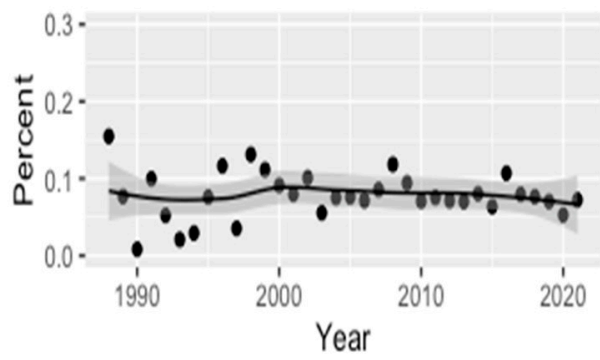

T9. Content Knowledge of Teachers

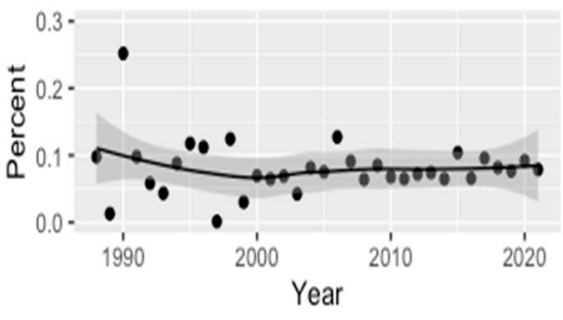

Note: The dot represents proportion of publications about a topic in a year.

\section{Discussion}

The purpose of this systematic review was to identify major research topics and research trends on mathematics teachers' knowledge. Specific research questions of the study were as follows: (1) How did overall research trends on mathematics teachers' knowledge evolve? (2) What were the frequently used words in the abstract? (3) What were the major research topics? (4) How and to what extent were the major research topics associated? and (5) How did individual research topics evolve? To answer these questions, we collected peer-review articles using Web of Science, Eric, and PsycInfo and retrieved 3485 articles with several inclusion and exclusion criteria. Then, we examined the retrieved data with a topic modeling approach. 
Regarding the first research question, we observed that the number of published articles on mathematics teachers' knowledge has steadily increased since 1987. Of the 3485 articles, 153 articles (4.3\%) were published during 1987-1999, and 2714 (77.9\%) articles were published during 2010-2021. Moreover, more than 300 articles have been published every year since 2017, which indicated a growing interest of researchers on mathematics teachers' knowledge. These results were aligned with the findings of Inglis and Foster [16] who reported increasing research on mathematics teachers' knowledge after analyzing articles in ESM and JRME. This could be due to the fact that mathematics teachers' knowledge considerably affected their instructional practices and student achievement [15]. Therefore, researchers have conducted various studies to enhance preservice and in-service mathematics teachers' knowledge [35], assess the level of their knowledge [37] and investigate the association between teacher knowledge, instructional methods, and student achievement [43].

As for the second research question, we examined frequently used words in abstracts and found that the following words were used more than 1000 times in abstracts: "teacher", "student", "teach", "learn", "develop", "preservice", "content", "practice", "understand", "classroom", "instruct", "professional", "pedagogy", "participation", and "concept". These keywords could indicate critical issues of research on mathematic teachers' knowledge.

To delve into the third research question, the major research topics were examined. The following 11 topics were found: "Professional Development" (T1), "Student Mathematical Understanding" (T2), "Knowledge Assessment" (T3), "Content Knowledge of Students" (T4), "Learning and Use of Educational Technology" (T5), "Preservice Teachers" (T6), "Pedagogical Content Knowledge" (T7), "Early Childhood Mathematics Education" (T8), "Content Knowledge of Teachers" (T9), "Instructional Methods and Student Achievement" (T10), and "Knowledge of Sociocultural Context" (T11). As previous scholars (e.g., [7,8,19]) have suggested knowledge of mathematical content, knowledge of mathematical teaching (e.g., knowledge of technological devices and instructional methods), and knowledge of learning mathematics (e.g., students' mathematical understanding) as a component of MTSK, these results are considered reasonable.

However, knowledge of mathematics learning standards (e.g., curricula) was not identified as a single topic. This implies that although scholars have proposed knowledge of learning standards as an important component that teachers should acquire, studies examining teachers' knowledge of mathematical standards are relatively limited. Moreover, knowledge of sociocultural context (T11) was identified as a distinctive topic. This result was interesting as previous scholars examining the components of mathematics teachers' knowledge rarely discussed knowledge of students' sociocultural context (e.g., [7]). Instead, they mainly focused on students' mathematical understanding and knowledge. However, the existence of the topic about knowledge of sociocultural context implies that mathematics scholars have examined not only SCK and PCK, but also teaching strategies and contextual issues (e.g., race, culture, or language issues) to support mathematics learning of minority students (e.g., [34]).

For research question four, we created an intertopic distance map and examined the relationship between topics. Based on the findings of research question 3 and the intertopic distance map, we reclassified the 11 topics into four groups to visually reveal their relationship. The first group was concerned with the assessment, such as assessment of teachers' and students' knowledge (T3) and students' achievement (T10). The second group was about mathematics teachers' knowledge for teaching, including pedagogical content knowledge (T7), content knowledge (T9), and knowledge of sociocultural context (T11). The third group was about students' mathematical knowledge and understanding, including T2, T4, and T8. The fourth group was about teachers' professional learning, such as professional development for in-service teachers (T1), learning of preservice teachers (T5), and learning and use of educational technology (T6). 
Previous scholars have suggested students' mathematical knowledge and understanding as a component of PCK. For example, Ball et al. [7] suggested knowledge of content and students to explain the characteristics of PCK. Similarly, Carrillo-Yañez et al. [8] proposed knowledge of features of learning mathematics as a component of PCK. Thus, it might be reasonable to incorporate the third group (students' mathematical knowledge and understanding) as a subdomain of the second group (mathematics teachers' knowledge for teaching). However, the intertopic distance map showed that the third group was a district group. This could be because the third group mainly focused on students' mathematical knowledge and comprehension to understand their mathematical abilities and characteristics, whereas the second group examined MTSK from a broader perspective. Moreover, the existence of assessment (group 1) and teachers' professional learning (group 4) imply that researchers have attended to enhancing mathematics teachers' knowledge and measuring the development of it (e.g., [44]).

To delve into research question five, the numbers of publications on each topic were examined across three time periods: (a) 1987-1999, (b) 2000-2009, and (c) 2010-2021. The analysis revealed that proportionally the numbers of publications of each topic were almost similar regardless of time periods. T1 $(19.9 \%)$ was the most studied topic, followed by T7 (10.5\%) and T2 (9.1\%), whereas T8 (5.9\%) was the least studied topic, followed by T5 $(7.1 \%)$ and $\mathrm{T} 4(7.2 \%)$. The examination of proportional change by year also revealed similar patterns (see Table 7). These findings implied that studies on professional development to improve mathematics teachers' knowledge (T1), examining mathematics teachers' PCK (T3), and analyzing student mathematical understanding (T2) were steadily emphasized by researchers. However, studies on early childhood mathematics education (T8), learning and use of educational technology (T5), content knowledge of students (T4) were not received large attention from mathematics educators. As studies on early childhood education and educational technology had their own distinct disciplinary field, these results were considered reasonable. The low percentage of T4 might be caused by the existence of $\mathrm{T} 2$, which examines similar topics. That is because studies on student mathematical understanding (T2) and student content knowledge (T4) were divided into different topics based on the topic modeling; T4 took relatively little proportion.

\section{Limitations}

This study has several limitations. The first limitation of the study is the use of three databases only: Web of Science, Eric, and PsycInfo. Therefore, adding articles from other databases might lead to different results; therefore, further studies can examine the same topics by adding more articles from other databases. The second limitation of the study is the exclusion of dissertations, thesis, and non-English written manuscripts. The third limitation of the study is the examination of words in abstracts only using LDA. While this approach is commonly used by researchers [14], the other information in the articles was ignored. The fourth limitation of the study is that the topic labels were relatively subjective. While LDA classified words in the abstract into different topics, researchers should determine their names. Various information was used to name topics, including top 15 characteristic words, a word could, and representative articles. However, future studies might use different topic labels, while they examine similar data. Therefore, further studies should be conducted to validate the findings of this study.

\section{Conclusions}

Over the past three decades, many studies have been conducted on mathematics teachers' knowledge. Despite the expansion of the field, a systematic review has rarely been conducted. Therefore, in this study, a topic modeling was implemented to synthesize previous studies and understand research topics and trends of the field. Based on the findings of this study, we suggest several implications. 
First, it is suggested that sociocultural context knowledge be included as a component of mathematics teachers' knowledge framework. Mathematics teachers' knowledge is defined as knowledge for teaching mathematics. Thus, mathematics teachers were expected to know students' strategies, understanding, misconceptions, and errors; however, it does not mean that mathematics teachers focus only on cognitive aspects of the students. Rather, effective mathematics teaching can start from analyzing student context to determine teaching strategies.

Students may need different teaching strategies based on their sociocultural backgrounds, and a teaching method that is effective for some students might not be effective for other students [34]. Therefore, mathematics teachers need to know sociocultural backgrounds of the students and redesign their teaching materials and methods to ensure all students have access to high-quality mathematics teaching and learning. The knowledge of sociocultural context may include knowledge for teaching mathematics to the English language learns. Moreover, sociocultural context knowledge is also aligned with equity issues [45]. National Council of Teachers of Mathematics (NCTM) [46] emphasized the importance of access and equity in mathematics education. This is because mathematics teachers should "empower all students to participate meaningfully in learning mathematics and to achieve outcomes in mathematics [regardless of] ... student characteristics" [46] (p. 60). Therefore, researchers need to consider incorporating sociocultural context knowledge into the knowledge framework of mathematics teachers.

Second, it would be valuable to implement further studies on mathematics teachers' knowledge of standards. Although it was not identified as a distinct topic from this study, many scholars have emphasized the importance of mathematics teachers' knowledge of standards [8]. Standards are defined as "statements of what students are expected to learn. [Moreover] standards are the ends" [46] (p. 70). Mathematics learning standards included knowledge of mathematical topic sequence and expected mathematics learning outcomes [8]. Consequently, the understanding of mathematical standards helps teachers not only achieve their teaching goals, but also decide on instructional materials and methods. Therefore, there is a need for additional studies on mathematics teachers' knowledge of standards. For example, we can measure teachers' knowledge of standards and examine the relationship between teachers' knowledge of standards and their instructional practices.

Third, it would be productive to examine various topics. The findings of this study showed that professional development is the most popular topic in examining the knowledge of mathematics teachers. This result was consistent throughout the time span from the 1980 s to the 2020s. High-quality mathematics teaching and learning is associated with the quality and quantity of research. The lack of research in one area may deteriorate the gap in teaching and learning in that area. For example, the topic of learning and use of educational technology has not received much attention over time, despite technology becoming ever more integrated into mathematics learning. These topics require further research from mathematics educators and researchers, because studies on educational technology could improve curriculum, teaching, learning, and assessment in mathematics education [47]. Moreover, researchers need to examine early childhood mathematics education, which received the least attention. High-quality and accessible mathematics education for preschoolers is a critical basis for future mathematics learning [48]. Therefore, further research may need to be conducted in this area.

We hope that this study can help scholars understand past and present research on mathematics teachers' knowledge and provide the groundwork for future studies.

Author Contributions: Conceptualization, S.H.; methodology, E.C.; software, E.C.; validation, S.H.; formal analysis, E.C.; investigation, S.H. and E.C.; resources, S.H.; data curation, S.H. and E.C.; writing-original draft preparation, S.H. and E.C.; writing-review and editing, S.H.; visualization, E.C.; supervision, S.H.; project administration, S.H. All authors have read and agreed to the published version of the manuscript.

Funding: This research received no external funding. 
Institutional Review Board Statement: Not applicable.

Informed Consent Statement: Not applicable.

Data Availability Statement: Not applicable.

Conflicts of Interest: The authors declare no conflict of interest.

\section{References}

1. Yang, X.R.; Kaiser, G.; Konig, J.; Blomeke, S. Relationship between Chinese mathematics teachers' knowledge and their professional noticing. Int. J. Sci. Math. Educ. 2021, 19, 815-837. [CrossRef]

2. Mohr-Schroeder, M.; Ronau, R.N.; Peters, S.; Lee, C.W.; Bush, W.S. Predicting student achievement using measures of teachers' knowledge for teaching geometry. J. Res. Math. Educ. 2017, 48, 520-566. [CrossRef]

3. Davis, B.; Simmt, E. Mathematics-for-teaching: An ongoing investigation of the mathematics that teachers (need to) know. Educ. Stud. Math. 2006, 61, 293-319. [CrossRef]

4. Even, R.; Tirosh, D. Teacher knowledge and understanding of students' mathematical learning. In Handbook of International Research in Mathematics Education; English, L., Ed.; Erlbaum: Mahwah, NJ, USA, 2002; pp. 219-240.

5. Peng, A. Knowledge growth of mathematics teachers during professional activity based on the task of lesson explaining. J. Math. Teach. Educ. 2007, 10, 289-299. [CrossRef]

6. Rowland, T.; Huckstep, P.; Thwaites, A. Elementary teachers' mathematics subject knowledge: The knowledge quartet and the case of Naomi. J. Math. Teach. Educ. 2005, 8, 255-281. [CrossRef]

7. Ball, D.L.; Thames, M.H.; Phelps, G. Content knowledge for teaching: What makes it special. J. Teach. Educ. 2008, 59, 389-407. [CrossRef]

8. Carrillo-Yañez, J.; Climent, N.; Montes, M.; Contreras, L.C.; Flores-Medrano, E.; Escudero-Ávila, D.; Vasco, D.; Rojas, N.; Flores, P.; Aguilar-González, Á.; et al. The mathematics teacher's specialised knowledge (MTSK) model. Res. Math. Educ. 2018, 20, 236-253. [CrossRef]

9. Depaepe, F.; Verschaffel, L.; Kelchtermans, G. Pedagogical content knowledge: A systematic review of the way in which the concept has pervaded mathematics educational research. Teach. Teach. Educ. 2013, 34, 12-25. [CrossRef]

10. Kim, R. Elementary teachers' knowledge for teaching mathematics: A review. Mediterr. J. Soc. Sci. 2014, 5, 428. [CrossRef]

11. Blömeke, S.; Delaney, S. Assessment of teacher knowledge across countries: A review of the state of research. ZDM Int. J. Math. Educ. 2012, 44, 223-247. [CrossRef]

12. Chen, X.; Zou, D.; Cheng, G.; Xie, H.R. Detecting latent topics and trends in educational technologies over four decades using structural topic modeling: A retrospective of all volumes of Computers \& Education. Comput. Educ. 2020, 151. [CrossRef]

13. Blei, D.M. Probabilistic topic models. Commun. ACM 2012, 55, 77-84. [CrossRef]

14. Yun, E. Review of trends in physics education research using topic modeling. J. Balt. Sci. Educ. 2020, 19, 388-400. [CrossRef]

15. Hill, H.C.; Rowan, B.; Ball, D.L. Effects of teachers' mathematical knowledge for teaching on student achievement. Am. Educ. Res. J. 2005, 42, 371-406. [CrossRef]

16. Inglis, M.; Foster, C. Five decades of mathematics education research. J. Res. Math. Educ. 2018, 49, 462-500. [CrossRef]

17. Shulman, L.S. Those who understand: Knowledge growth in teaching. Educ. Res. 1986, 15, 4-14. [CrossRef]

18. Fennema, E.; Franke, M.L. Teachers' knowledge and its impact. In Handbook of Research on Mathematics Teaching and Learning; Grouws, D.A., Ed.; Macmillan: New York, NY, USA, 1992; pp. 147-164.

19. Shulman, L.S. Knowledge and teaching: Foundations of the new reform. Harv. Educ. Rev. 1987, 57, 1-22. [CrossRef]

20. Marks, R. Pedagogical content knowledge: From a mathematical case to a modified conception. J. Teach. Educ. 1990, 41, 3-11. [CrossRef]

21. Blömeke, S.; Suhl, U.; Kaiser, G. Teacher education effectiveness: Quality and equity of future primary teachers' mathematics and mathematics pedagogical content knowledge. J. Teach. Educ. 2011, 62, 154-171. [CrossRef]

22. Baumert, J.; Kunter, M.; Blum, W.; Brunner, M.; Voss, T.; Jordan, A.; Klusmann, U.; Krauss, S.; Neubrand, M.; Tsai, Y.-M. Teachers' mathematical knowledge, cognitive activation in the classroom, and student progress. Am. Educ. Res. J. 2010, 47, 133-180. [CrossRef]

23. Nilssen, V.L. Guided planning in first-year student teachers' teaching. Scand. J. Educ. Res. 2010, 54, 431-449. [CrossRef]

24. Aguilar-González, Á.; Muñoz-Catalán, M.C.; Carrillo, J. An example of connections between the mathematics teacher's conceptions and specialised knowledge. Eurasia J. Math. Sci. Tech. Educ. 2019, 15, em1664. [CrossRef]

25. Blei, D.M.; Ng, A.Y.; Jordan, M.I. Latent dirichlet allocation. J. Mach. Learn. Res. 2003, 3, 993-1022.

26. Dobie, T.E.; Sherin, B. The language of mathematics teaching: A text mining approach to explore the zeitgeist of US mathematics education. Educ. Stud. Math. 2021, 107, 159-188. [CrossRef]

27. Hwang, G.-J.; Tu, Y.-F. Roles and research trends of artificial intelligence in mathematics education: A bibliometric mapping analysis and systematic review. Mathematics 2021, 9, 584. [CrossRef]

28. Sievert, C.; Shirley, K. LDAvis: A method for visualizing and interpreting topics. In Proceedings of the the Workshop on Interactive Language Learning, Visualization, and Interfaces, Baltimore, MD, USA, 27 June 2014; pp. 63-70.

29. Honicke, T.; Broadbent, J. The influence of academic self-efficacy on academic performance: A systematic review. Educ. Res. Rev. 2016, 17, 63-84. [CrossRef] 
30. Schofield, A.; Mimno, D. Comparing apples to apple: The effects of stemmers on topic models. Trans. Assoc. Comput. Linguist. 2016, 4, 287-300. [CrossRef]

31. Cao, J.; Xia, T.; Li, J.; Zhang, Y.; Tang, S. A density-based method for adaptive LDA model selection. Neurocomputing 2009, 72, 1775-1781. [CrossRef]

32. Jacobi, C.; Van Atteveldt, W.; Welbers, K. Quantitative analysis of large amounts of journalistic texts using topic modelling. Digit. J. 2016, 4, 89-106. [CrossRef]

33. Gasteiger, H.; Bruns, J.; Benz, C.; Brunner, E.; Sprenger, P. Mathematical pedagogical content knowledge of early childhood teachers: A standardized situation-related measurement approach. ZDM Int. J. Math. Educ. 2020, 52, 193-205. [CrossRef]

34. Bonner, E.P. Investigating practices of highly successful mathematics teachers of traditionally underserved students. Educ. Stud. Math. 2014, 86, 377-399. [CrossRef]

35. Turner, F. Using the Knowledge Quartet to develop mathematics content knowledge: The role of reflection on professional development. Res. Math. Educ. 2012, 14, 253-271. [CrossRef]

36. Spangenberg, E.D.; Pithmajor, A.K. Grade 9 mathematics learners' strategies in solving number-pattern problems. Eurasia J. Math Sci. Tech. Educ. 2020, 16, em1862. [CrossRef]

37. Tchoshanov, M.; Quinones, M.C.; Shakirova, K.B.; Ibragimova, E.N.; Shakirova, L.R. Analyzing connections between teacher and student topic-specific knowledge of lower secondary mathematics. J. Math. Behav. 2017, 47, 54-69. [CrossRef]

38. Tunç-Pekkan, Z. An analysis of elementary school children's fractional knowledge depicted with circle, rectangle, and number line representations. Educ. Stud. Math. 2015, 89, 419-441. [CrossRef]

39. Bozkurt, G.; Ruthven, K. Classroom-based professional expertise: A mathematics teacher's practice with technology. Educ. Stud. Math. 2017, 94, 309-328. [CrossRef]

40. Chapman, O. Facilitating preservice teachers' development of mathematics knowledge for teaching arithmetic operations. J. Math Teach. Educ. 2007, 10, 341-349. [CrossRef]

41. Chick, H.; Beswick, K. Teaching teachers to teach Boris: A framework for mathematics teacher educator pedagogical content knowledge. J. Math. Teach. Educ. 2018, 21, 475-499. [CrossRef]

42. Levenson, E. Teachers' knowledge of the nature of definitions: The case of the zero exponent. J. Math. Behav. 2012, 31, 209-219. [CrossRef]

43. Kutnick, P.; Fung, D.C.L.; Mok, I.A.C.; Leung, F.K.S.; Li, J.C.H.; Lee, B.P.Y.; Lai, V.K.W. Implementing effective group work for mathematical achievement in primary school classrooms in Hong Kong. Int. J. Sci. Math. Educ. 2017, 15, 957-978. [CrossRef]

44. Campbell, M.P.; Lee, H.S. Examining secondary mathematics teachers' opportunities to develop mathematically in professional learning communities. Sch. Sci. Math. 2017, 117, 115-126. [CrossRef]

45. Healy, L.; Powell, A.B. Understanding and overcoming "disadvantage" in learning mathematics. In Third International Handbook of Mathematics Education; Clements, M.A.K., Bishop, A.J., Keitel, C., Kilpatrick, J., Leung, F.K.S., Eds.; Springer: New York, NY, USA, 2012; pp. 69-100.

46. NCTM. Principles to Actions: Ensuring Mathematical Success for All; NCTM: Reston, VA, USA, 2014.

47. Clements, M.A. Past, present and future dimensions of mathematics education: Introduction to the third international handbook of mathematics education. In Third International Handbook of Mathematics Education; Clements, M.A.K., Bishop, A.J., Keitel, C., Kilpatrick, J., Leung, F.K.S., Eds.; Springer: New York, NY, USA, 2012; pp. v-xi.

48. Shanley, L. Evaluating longitudinal mathematics achievement growth: Modeling and measurement considerations for assessing academic progress. Educ. Res. 2016, 45, 347-357. [CrossRef] 